\title{
Visualization of Active and Passive Control of Morphology during Electrodeposition
}

\author{
Nicholas M. Schneider ${ }^{1}$, Jeung Hun Park ${ }^{2}$, Joseph M. Grogan ${ }^{1,3}$, Suneel Kodambaka ${ }^{2}$, Daniel A. \\ Steingart ${ }^{4}$ Frances M. Ross ${ }^{5}$, and Haim H. Bau ${ }^{1}$ \\ 1. University of Pennsylvania, Philadelphia, PA 19104, USA. \\ 2. University of California Los Angeles, Los Angeles, CA 90095, USA. \\ ${ }^{3 .}$ Hummingbird Scientific, Lacey, WA 98516, USA \\ 4. Princeton University, Princeton, NJ 08544, USA. \\ 5. IBM T. J. Watson Research Center, Yorktown Heights, NY 10598, USA.
}

Morphological instability, particularly dendrite formation, can cause potentially catastrophic failure in rechargeable batteries. Morphological instabilities can lower the quality of electroplated coatings, yet may also be useful in forming porous deposits. Thus, it is important to develop strategies to control these instabilities. Liquid cell electron microscopy allows us to image in real time and with nanoscale resolution the evolution of the solid-liquid interface during electrochemical deposition as a function of process conditions [1-3]. This allows us to obtain insights into the mechanisms leading to instabilities and to investigate strategies for controlling electrodeposited morphology.

Several strategies have been proposed to suppress growth instabilities. One approach is to use a flowing electrolyte [4]. Another is to include additives in the electrolyte that modify the growth kinetics [5]. Finally, modulating the current by periodically pausing current flow allows the cation concentration that is locally depleted near the interface to level out, favoring uniform growth. In order to assess the effectiveness of these mechanisms, it is useful to examine the onset of growth instabilities in-situ.

Here, we investigate the growth front during the deposition and stripping of copper in an acidified copper sulphate solution with liquid cell electron microscopy. We examine active control, i.e., the effects of current pulsing, as well as passive control such as the presence of lead as an inorganic additive. The experiments were carried out with our custom made liquid cell, the nanoaquarium [6], operating in a three terminal configuration with Pt electrodes controlled by a Gamry potentiostat. The interface morphology evolution was imaged at video rate (30 images per second) as a function of current density, current pulsing and solution composition, in a Hitachi H-9000 TEM at 300kV. Fig. 1 presents images of the interface recorded under different conditions. In the absence of control and additives, the growth front propagates smoothly and no dendrites are visible at low current density (Fig. 1a, growth rate $1.4 \mathrm{~nm} / \mathrm{s}$ ). At higher current density (average growth rate $39 \mathrm{~nm} / \mathrm{s}$ ), there is a period of roughening until 200nm $\mathrm{Cu}$ has grown (which takes a few seconds) after which dendrites form rapidly (Fig. 1b). However, at similar growth rates, no dendrites are visible when the current is pulsed (Fig. 1c) and no roughening is visible in the presence of the additive lead (Fig. 1d), which maintains a roughness level less than that of the low current density (Fig. 1a).

We used the RMS roughness of the growth front to quantify the onset of instability and identify the transition from uniform growth to dendritic growth as a function of current density, solution composition, and pulse times (Fig. 2). Fig. 2a shows that at low current density the surface does roughen but this takes place only slowly. However, increasing the current density leads to a dramatic transition, clearly seen in Fig. 2b, where the rate of roughening increases rapidly after about 200nm of growth. 
Pulsed growth results in a surface that roughens only slowly (Fig. 2c) and avoids the dendrites found in the continuous growth. Lastly, the lead additive results in an essentially constant roughness inherited from the underlying substrate (Fig. 2d). The RMS roughness analysis thus gives a quantitative measure of how both pulsed current and additives help avoid dendrite formation. We will discuss the modeling of these results and the implications for morphology control during electrodeposition of metal films [7].
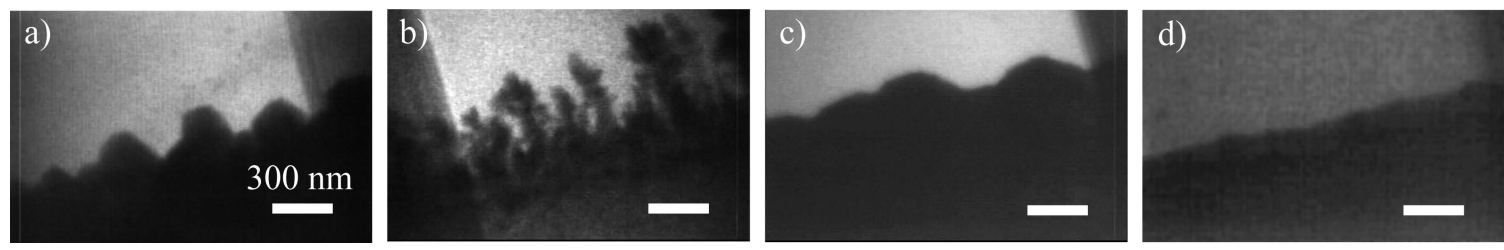

Figure 1. Instantaneous micrographs of the growth interface for $\mathrm{Cu}$ deposition from acidified $\mathrm{CuSO}_{4}$. $(\mathrm{a}, \mathrm{b})$ Growth at $1.4 \mathrm{~nm} / \mathrm{s}$ and $39 \mathrm{~nm} / \mathrm{s}$ with neither additives nor current pulsing, (c) The interface under pulsed deposition (1 sec pulses) growing at an average rate of $50 \mathrm{~nm} / \mathrm{s}$. (d) Growth in the presence of a lead additive (saturated $\mathrm{PbSO}_{4}$ ) at $36 \mathrm{~nm} / \mathrm{s}$. Growth velocities are measured as the average final growth height divided by the time interval during which the current was supplied.
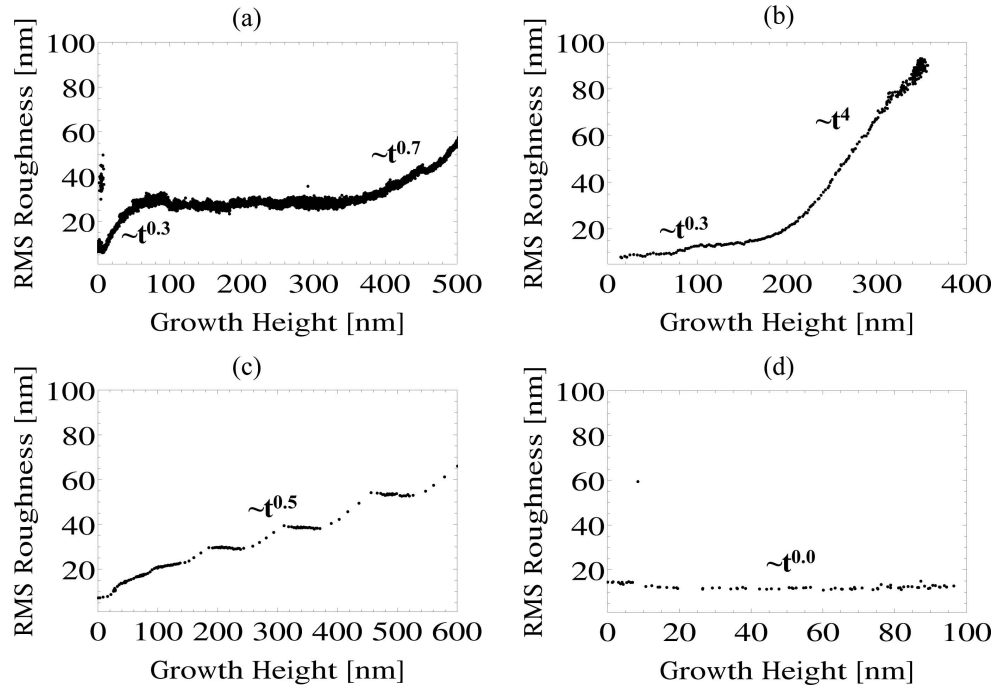

Figure 2. RMS roughness as a function of average growth height, extracted from videos in Fig. 1.

\section{References:}

[1] J. M. Grogan, N. M. Schneider, F. M. Ross and H. H. Bau, J. Indian Inst. Sei. 92 (2012), p. 295.

[2] N. de Jonge and F. M. Ross, Nature Nanotech. 6 (2011), p. 695.

[3] M. J. Williamson, R. M. Tromp, P. M. Vereecken, R. Hull and F. M. Ross, Nature Mater. 2 (2003) p. 532.

[4] Y. Ito, M. Nyce, R. Plivelich, M. Klein, D. Steingart and S. Banerjee, J. Power Sources 196 (2011), p. 2340.

[5] A. C. West, Electrochemistry and Electrochemical Engineering: An Introduction. CreateSpace Independent Publishing Platform, 2012.

[6] J. M. Grogan and H. H. Bau, J. Microelectromech. Syst. 19 (2010), p. 885-894.

[7] The authors acknowledge funding, in part, from the NSF, grants 1129722, 1066573, 1031208, 1310639, and 1402872. Microscopy was performed at the IBM T. J. Watson Research Center with the valuable experimental contributions of Dr. Mark C. Reuter and Mr. Arthur Ellis of IBM. 